\title{
PREPARATION AND CHARACTERISTICS OF HIGHLY MICROPOROUS ACTIVATED CARBON DERIVED FROM EMPTY FRUIT BUNCH OF PALM OIL USING KOH ACTIVATION
}

\author{
Allwar Allwar \\ Department of Chemistry, Faculty Mathematics, and Natural Sciences, \\ Universitas Islam Indonesia \\ E-mail: allwar@uii.ac.id
}

\begin{abstract}
Empty fruit bunch of oil palm was used as an alternative raw material for preparation of highly microporous activated carbon. Activated carbon was prepared by impregnation of raw material using $65 \%$ of potassium hydroxide and carbonized at different activation temperatures. The nitrogen adsorption-desorption isotherms at $77 \mathrm{~K}$ exhibited the Type I at lower temperatures relating to the microporous structure. However, the nitrogen isotherm at $800^{\circ} \mathrm{C}$ showed Type IV with high hysteresis loop clearly showing the forming the mesopore. The Langmuir surface area increased with increasing activation temperature which the highest surface area was $1197 \mathrm{~m}^{2} \mathrm{~g}^{-1}$. Surface chemistry of the activated carbon showed high oxygen surface, functional groups. Morphology structure of activated carbon was clearly exhibited highly porous activated carbon.
\end{abstract}

Keywords: Empty fruit bunch, activated carbon, potassium hydroxide, micropores, surface area

(C) RASĀYAN. All rights reserved

\section{INTRODUCTION}

Activated carbon is a well-known porous material with wide ranges of chemical and physical properties. Chemical properties such as functional groups on the surface of activated carbon affect their reactivity in the catalyst process. The important physical properties such surface area and porosity can impact the quality and utility of activated carbon as the adsorbent. ${ }^{1,2}$ Physical properties play important roles in purification and separation process which mostly used in industrial and environmental applications. The specific surface area was commonly used for separation and purification, wastewater treatments, capacitors and catalyst supports. Surface area measurement determined the accessibility of active site for the catalytic activities. ${ }^{3}$ Pore size distribution was separated into two classes: micropores (pore diameter $<2 \mathrm{~nm}$ ) and mesopores (pore diameter $2-50 \mathrm{~nm}$ ) which are requested to improve the solid particles performance involving inside porous networks and facilitate the adsorption. ${ }^{4,5}$

Surface chemistry on the external surface activated carbons has a considerable effect on their chemical reactivity by a chemical bond. Surface functional groups containing the oxygen and nitrogen may increase free valences on the edges of the external surface which are very reactive. The oxygen and nitrogen functional groups may act to form coordination chemistry in attracting heavy metals in aqueous and nonaqueous solutions for the treatment of waste and toxic effluence. ${ }^{6}$

Raw material with high carbon materials such as biomass solid waste has a considerable effect to prepare activated carbon. However, porous structures of the obtained activated carbon can be influenced not only the type of raw materials but also on the appropriate methods. Activated carbon can be obtained by two different methods: physical and chemical processes. ${ }^{7}$ In the physical process, the raw material was carbonized at a high temperature in absence of air and any of chemicals. The results are usually activated carbon with low quality of pore structure. To prepared activated carbon by chemical activation, the raw material was impregnated by activating agents such as phosphoric acid, potassium hydroxide, sodium carbonate, sodium hydroxide, potassium carbonate, phosphoric acid, zinc chloride, etc. The impregnated 
sample was pyrolyzed under nitrogen, carbon dioxide or steam. ${ }^{8,9}$ The important activation is to initiate a well-developed microporous structure by the removal of tars-clogging and followed by enlarge of the surface area ${ }^{10}$. Some advantages of preparation activated carbon using chemical activation were the quality of pore structures and low-cost operation processes. For commercial, biomass waste or agricultural solid waste was favorably used as a raw material for the preparation of activated carbon due to it available in large quantity. ${ }^{11,12}$

The objective of this work was to maintain a clean environment as well as to achieve a vision of zerowaste strategy of palm oil industry, research and development activities were focused on the utility of biomass solid wastes empty fruit bunch (EFB) as an alternative precursor for manufacturing activated carbon. The use of empty fruit bunch has some advantages such as low-cost materials, available in large quantity and environmental advantages. In addition, highly-porous activated carbons from biomass empty fruit bunch were prepared by the physical and chemical activation processes ${ }^{13}$. Characterizations of activated carbon were observed for determination of pore structures (Quantachrome Nova 2200e), surface areas (FTIR) and morphology structure (SEM-EDX).

\section{Materials}

\section{EXPERIMENTAL}

The empty fruit bunch (EFB) of palm oil was taken from an open area at around the palm oil industry. EFB was washed to reduce oil contents and dried under sunlight light for few days. Dried EFB was cut down into a small particle in the range of $0.5-1.5 \mathrm{~mm}$. The chemicals such as potassium hydroxide $(\mathrm{KOH})$, hydrochloric acid $(\mathrm{HCl})$ were obtained from E Merck.

\section{Preparation of activated carbon from empty fruit bunch}

Dried EFB as much as $250 \mathrm{~g}$ was impregnated with $750 \mathrm{ml}$ of $65 \% \mathrm{KOH}$ solution. The mixture was refluxed under water batch at $85^{\circ} \mathrm{C}$ for $24 \mathrm{~h}$. After cooling down, the mixture was washed with distilled water while neutralization process by dropping of $0.5 \mathrm{M}$ of $\mathrm{HCl}$ solution and dried into the oven at $110^{\circ} \mathrm{C}$. Dried EFB sample was placed inside the reactor and set up into graphite furnace for carbonization process. Once the temperature of carbonization increased to $100^{\circ} \mathrm{C}$ with heating rate $5^{\circ} \mathrm{C} \mathrm{min}^{-1}$, the purified nitrogen gas flowed into the reactor at the constant rate $200 \mathrm{~cm}^{3} \mathrm{~min}^{-1}$. Carbonization temperature was in the range of $500-800^{\circ} \mathrm{C}$ with a contact times $3 \mathrm{~h}$. Thereafter, the temperature was automatically stopped and followed by cooling down the process to room temperature. The EFB inside the reactor was taken it out and washed few times to neutral condition at $\mathrm{pH}$ 6-7. Next step, the similar procedure was continued under purified carbon dioxide in place of nitrogen gas for $1.5 \mathrm{~h}$. The results of carbonization were EFB activated carbon and kept into desiccator for further analysis

\section{Elemental Analysis}

\section{RESULTS AND DISCUSSION}

Elemental analysis of EFB was obtained at previous work. The results were displayed in form of proximate analysis (29\% fix carbon) and ultimate analysis (43.7\% carbon content). It was assumed that EFB has a good alternative for the raw material of activated carbon production.

\section{Effect of Temperatures on the Adsorption}

The effect temperatures on the adsorption of activated carbon were displayed in Fig.-1. The results showed that the percentage yields of activated carbon decreased with the increasing activation temperatures. At higher temperature, more volatile components in the EFB would be released and more ash contents would be obtained. The final yields of activated carbon were obtained at around 8-24\%. The percentage of obtained activated carbon was defined as:

$$
\text { Yield }(\%)=\frac{\text { weight of produts }}{\text { weight of dried sample }} X 100 \%
$$


RASĀYAN J. Chem.

Vol. 11 | No. 1 |280 - 286 | January - March | 2018

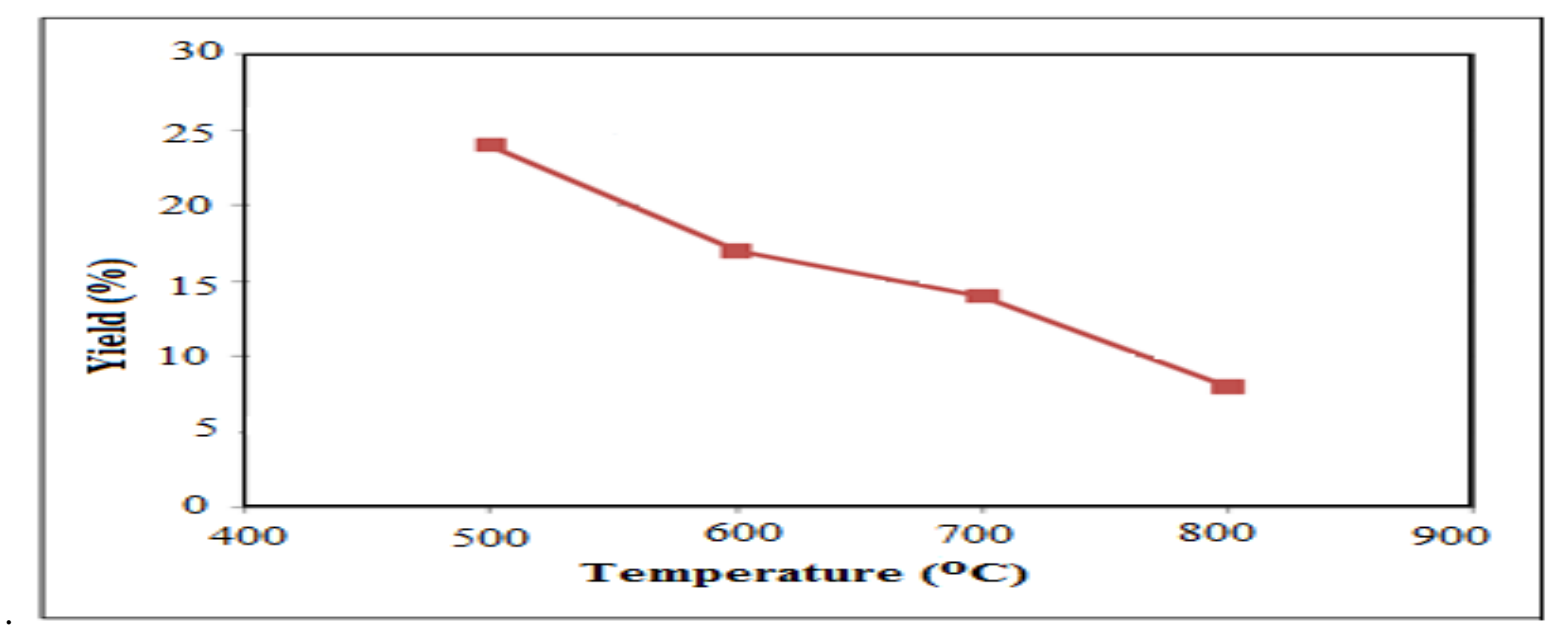

Fig.-1: Effect of temperatures on the activated carbon yields

\section{Nitrogen adsorption-desorption isotherms}

The nitrogen adsorption-desorption isotherms data were used to evaluate the properties of activated carbons. Prior to analysis, $0.5-1.0 \mathrm{~g}$ of activated carbon was degassed at a temperature of $250^{\circ} \mathrm{C}$ for $8 \mathrm{~h}$. In the physisorption process, high-purified nitrogen gas was used as adsorbates, and liquid nitrogen was used as a coolant at $77 \mathrm{~K}$. Measurements of nitrogen adsorption-desorption isotherms were carried out at a wide range of relative pressures of $0.00-0.99$. Figure- 2 showed the effect of temperatures on the nitrogen isotherms plot of the activated carbon. The plots obtained at 500 and $600^{\circ} \mathrm{C}$ showed open-ended shapes at low relative pressures. Low temperatures might cause the incomplete combustion resulting shrinkage pore during carbonization process. In addition, it was not enough energy to convert of raw material to form pore structures. However, the nitrogen isotherms at 700 and $800^{\circ} \mathrm{C}$ exhibited close-ended shapes at low relative pressures provided an improvement of pore structures. In general, the plots of nitrogen isotherms show Type I and IV indicating the presence of the micro- and mesoporous activated carbon. A broad hysteresis loop at $800^{\circ} \mathrm{C}$ was attributed to the existences of wider micropores and narrow mesopores with capillary condensation.

\section{Surface Area and Pore Volume}

Surface area and micropore volume were the important physical properties which impact the adsorption capacity of an adsorbent. Measurements of surface area and micropore volume were conducted by the Langmuir and Dubinin-Radushkevich methods, respectively. The Langmuir plots were obtained at a low relative pressure in the range of $0.01-0.05$ and presented in Fig.-3. Langmuir plots were consistent with the Type I and IV isotherm relating with micropores and mesopores. The micropore volume and micropore surface area were estimated from the adsorption data at a relative pressure less than 0.05 using the Dubinin-Radushkevich method, and total pore volume was calculated at a single point at highest relative pleasure $\left(\mathrm{p} / \mathrm{p}_{\mathrm{o}}=0.99\right)$. Table -1 shows the textural characteristics based on the effect of temperatures. The activated carbon prepared at $500^{\circ} \mathrm{C}$ showed a Langmuir plot which did not overlap between the plot and based line. It could be assumed as a rudimentary porous structure. This may be due to the incomplete heating process. The results of textural characteristics provided the lowest values. It was also supported by the presence of open-ended isotherm at low relative pressure. However, the increasing temperatures to $800^{\circ} \mathrm{C}$ enhanced to the removal of the major component in the raw materials and further created new pores, resulting in improvement of porous structures of the activated carbon. It indicated that the effects of temperature played important roles in developing porous structures.

\section{Pore Size Distributions}

Figure -4 shows pore size distribution using the Dubinin-Astakhov method at different temperatures. In general, maximum peaks of micropore distributions were below $2 \mathrm{~nm}$ which indicated the essentially 
microporous activated carbon. As seen in Table-1, the micropore diameters were in the range of 1.52-1.74 $\mathrm{nm}$, characteristics of narrower microporous activated carbon.

It was clearly seen that the effects of temperature were significant factors to widening porous structures. The qualitative information about the micropore size distribution was also obtained from the DubininAstakhov exponential values (n) which associates to the width of the energy distribution in the microporosity. ${ }^{14}$ Table-1 showed that all the exponent values (n) of the activated carbons were in the ranges of 1.8-1.9 which indicated the heterogeneous activated carbon with wide range of micropores.

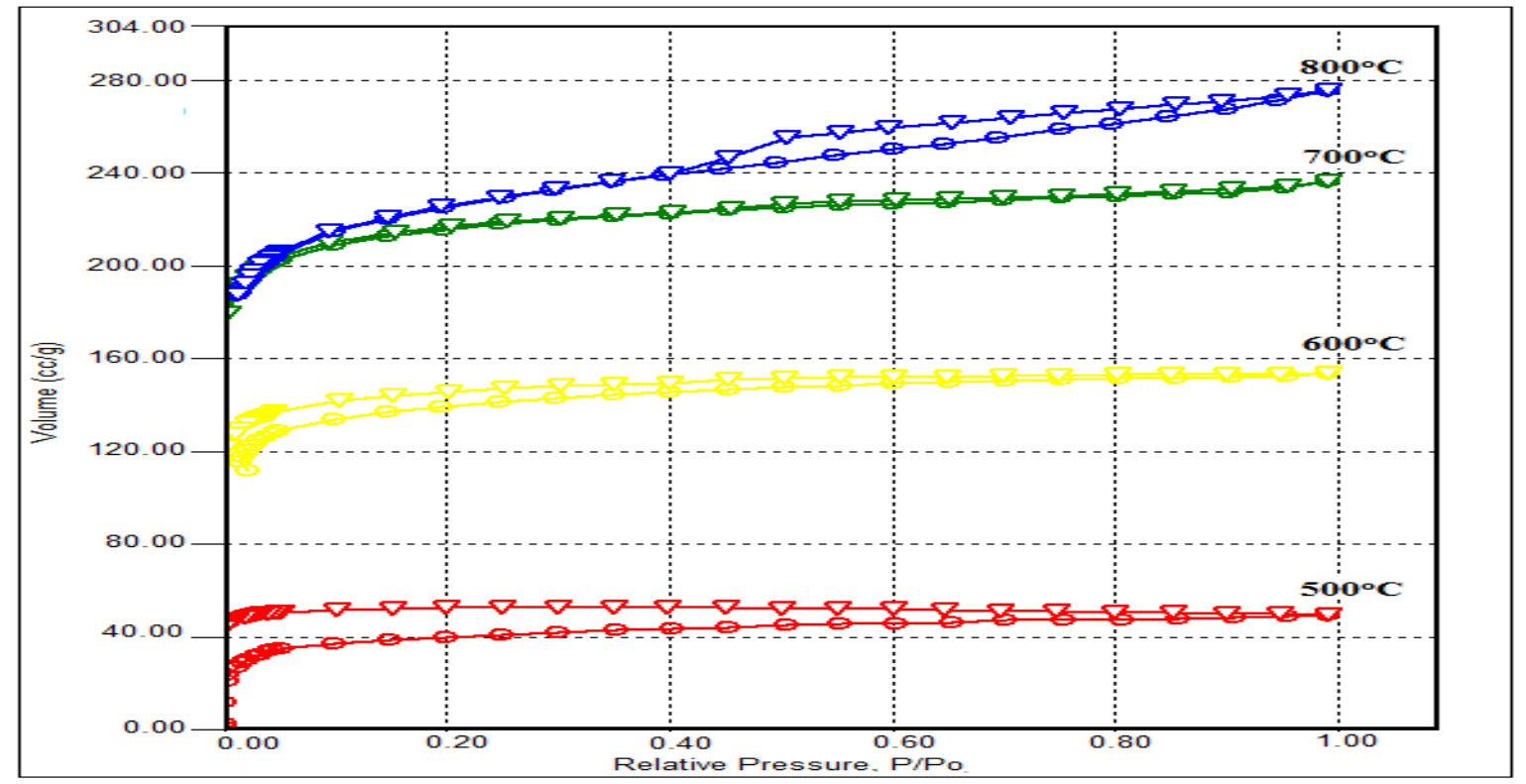

Fig.-2: Nitrogen adsorption-desorption isotherms at $77 \mathrm{~K}$ of activated carbons

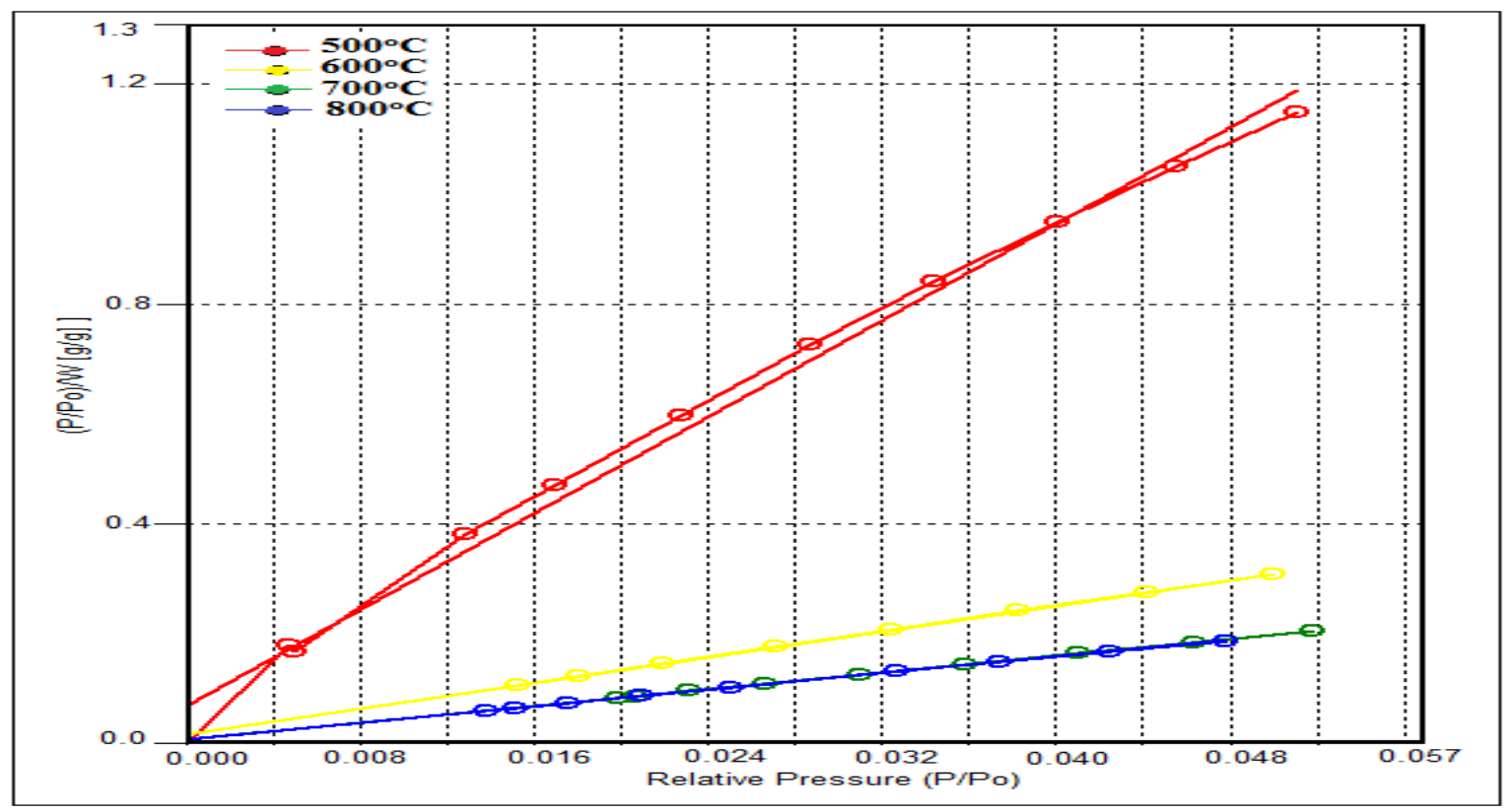

Fig.-3: Influence of temperatures on the Langmuir plot 
RASĀYAN J. Chem.

Vol. 11 | No. 1 |280 - 286 | January - March | 2018

Table -1: Textural properties of activated carbons

\begin{tabular}{|c|c|c|c|c|c|c|}
\hline \multirow[t]{2}{*}{ Gas } & \multirow{2}{*}{$\begin{array}{l}\text { Temp } \\
\left({ }^{\circ} \mathrm{C}\right)\end{array}$} & \multirow{2}{*}{$\begin{array}{c}\text { Langmuir } \\
\text { Surface area } \\
\left(\mathrm{m}^{2} \mathrm{~g}^{-1}\right)\end{array}$} & \multicolumn{2}{|c|}{ Dubinin-Radushkevich } & \multirow{2}{*}{$\begin{array}{c}\text { Total pore } \\
\text { volume } \\
(\mathrm{p} / \mathrm{po}=0.99) \\
\left(\mathrm{cm}^{3} \mathrm{~g}^{-1}\right)\end{array}$} & \multirow{2}{*}{$\begin{array}{c}\mathrm{D}-\mathrm{A} \\
\text { Micropore } \\
\text { diameter } \\
(\mathrm{nm})\end{array}$} \\
\hline & & & $\begin{array}{c}\text { Micropore } \\
\text { volume }\left(\mathrm{cm}^{3} \mathrm{~g}^{-1}\right)\end{array}$ & $\begin{array}{c}\text { Micropore } \\
\text { surface area } \\
\left(\mathrm{m}^{2} \mathrm{~g}^{-1}\right)\end{array}$ & & \\
\hline $\mathrm{KOH}$ & $\begin{array}{l}500 \\
600 \\
700 \\
800\end{array}$ & $\begin{array}{c}157 \\
592 \\
913 \\
1179\end{array}$ & $\begin{array}{l}0.05 \\
0.22 \\
0.34 \\
0.35\end{array}$ & $\begin{array}{l}146 \\
631 \\
947 \\
971\end{array}$ & $\begin{array}{l}0.08 \\
0.24 \\
0.37 \\
0.43\end{array}$ & $\begin{array}{l}1.74(\mathrm{n}=1.9) \\
1.60(\mathrm{n}=1.9) \\
1.52(\mathrm{n}=1.9) \\
1.56(\mathrm{n}=1.8)\end{array}$ \\
\hline
\end{tabular}

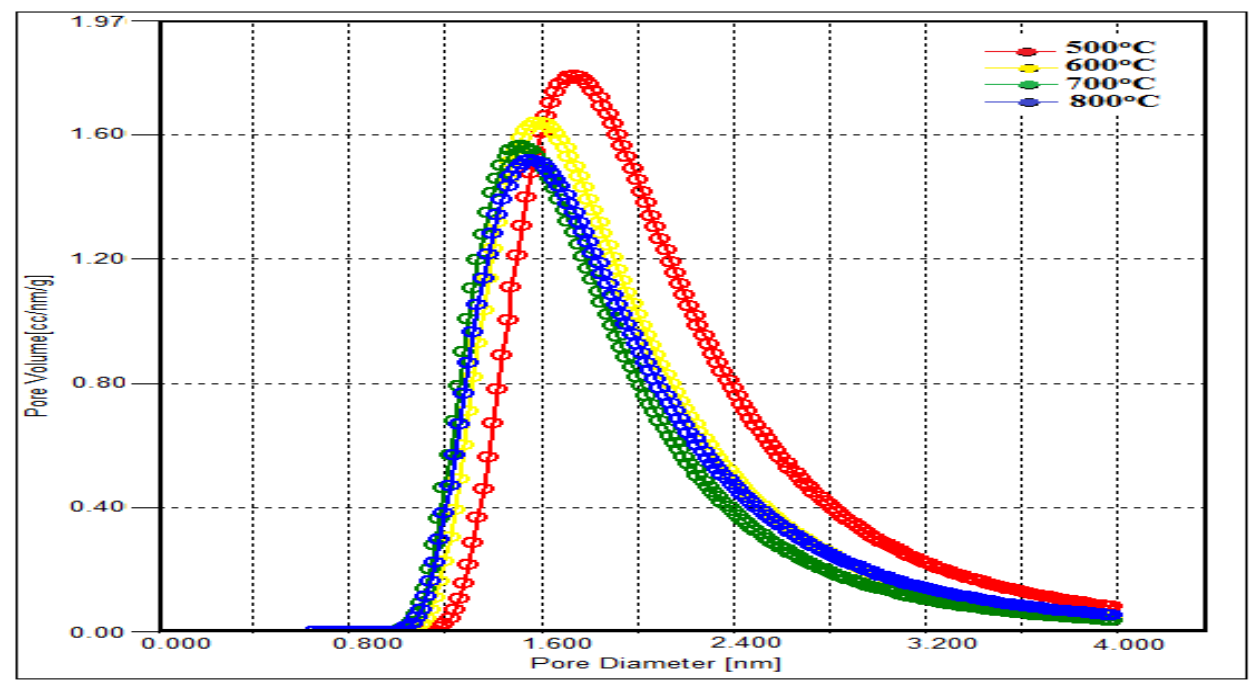

Fig.-4: The influence of Dubinin-Astakhov micropore at different temperatures

\section{Effect of Temperatures on the Functional Groups}

Figure -5 showed the FT-IR spectra of EFB activated carbon which was observed at wavenumber in the range of $4000-400 \mathrm{~nm}$. The presence of a peak at $3404 \mathrm{~cm}^{-1}$ was assigned as stretching vibration oh $\mathrm{O}-\mathrm{H}$ in hydroxyl groups. A weak peak at $1691 \mathrm{~cm}^{-1}$ was ascribed as stretching vibration of $\mathrm{C}=\mathrm{O}$ groups. This band disappeared at increasing temperatures. The strong band at $1564 \mathrm{~cm}^{-1}$ was attributed to $\mathrm{C}=\mathrm{C}$ stretching in aromatic rings which was almost disappeared as increased temperatures. The bands at 1442 and $1383 \mathrm{~cm}^{-1}$ were ascribed to $\mathrm{C}=\mathrm{O}$ and $\mathrm{C}-\mathrm{O}$ stretching vibration, respectively in carbonyl, ester and carboxylate groups. The bands at $1079 \mathrm{~cm}^{-1}$ were ascribed to $\mathrm{C}-\mathrm{O}$ stretching vibrations in hydroxyl groups, and shows a stronger intensity at higher temperatures ${ }^{15}$. The presences of bands around $874-752$ $\mathrm{cm}^{-1}$ were assigned to $\mathrm{C}-\mathrm{H}$ out-of-plane deformation vibration of $\mathrm{C}-\mathrm{H}$ groups located at the edges of benzene derivate which were lesser intensities at higher temperatures ${ }^{16,17}$. The FTIR studies of the surface functional groups revealed that the activated carbons proved more oxygen functional groups at higher temperatures.

\section{Structural Morphology and Elemental Analysis}

The SEM and EDX were used to observe the surface morphology and chemical compositions of the activated carbon. Empty fruit bunch activated carbon prepared at $700^{\circ} \mathrm{C}$ was selected to study its structural morphologies. Figure -6 shows morphology structure and elemental micro-analysis. The result showed that empty fruit bunch activated carbon has highly porous materials with a well-developed porous structure. The external structure was full of the cavities. The elemental micro-analysis provided a weight of carbon $(84.37 \%)$, oxygen $(12.65 \%)$ and magnesium $(2.96 \%)$. 
RASĀYAN J. Chem.

Vol. 11 | No. 1 | 280 - 286 | January - March | 2018

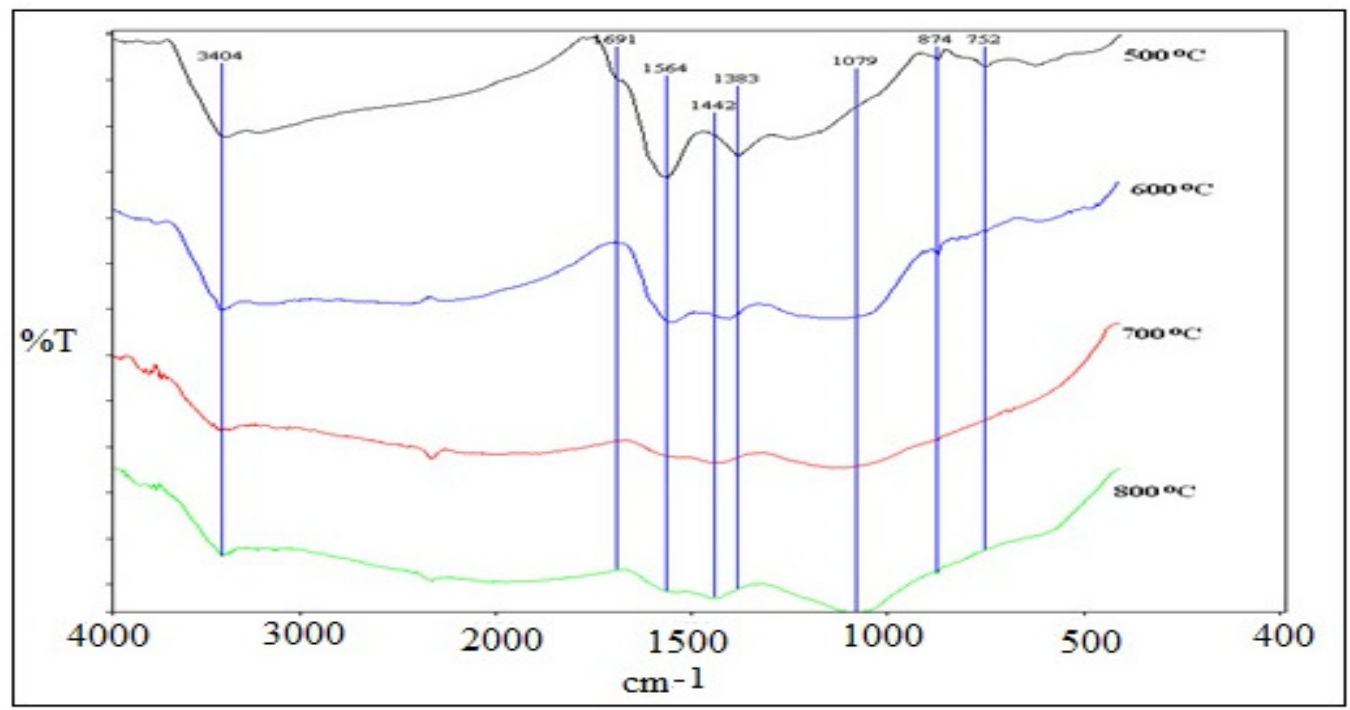

Fig.-5: The FT-IR spectra of activated carbon
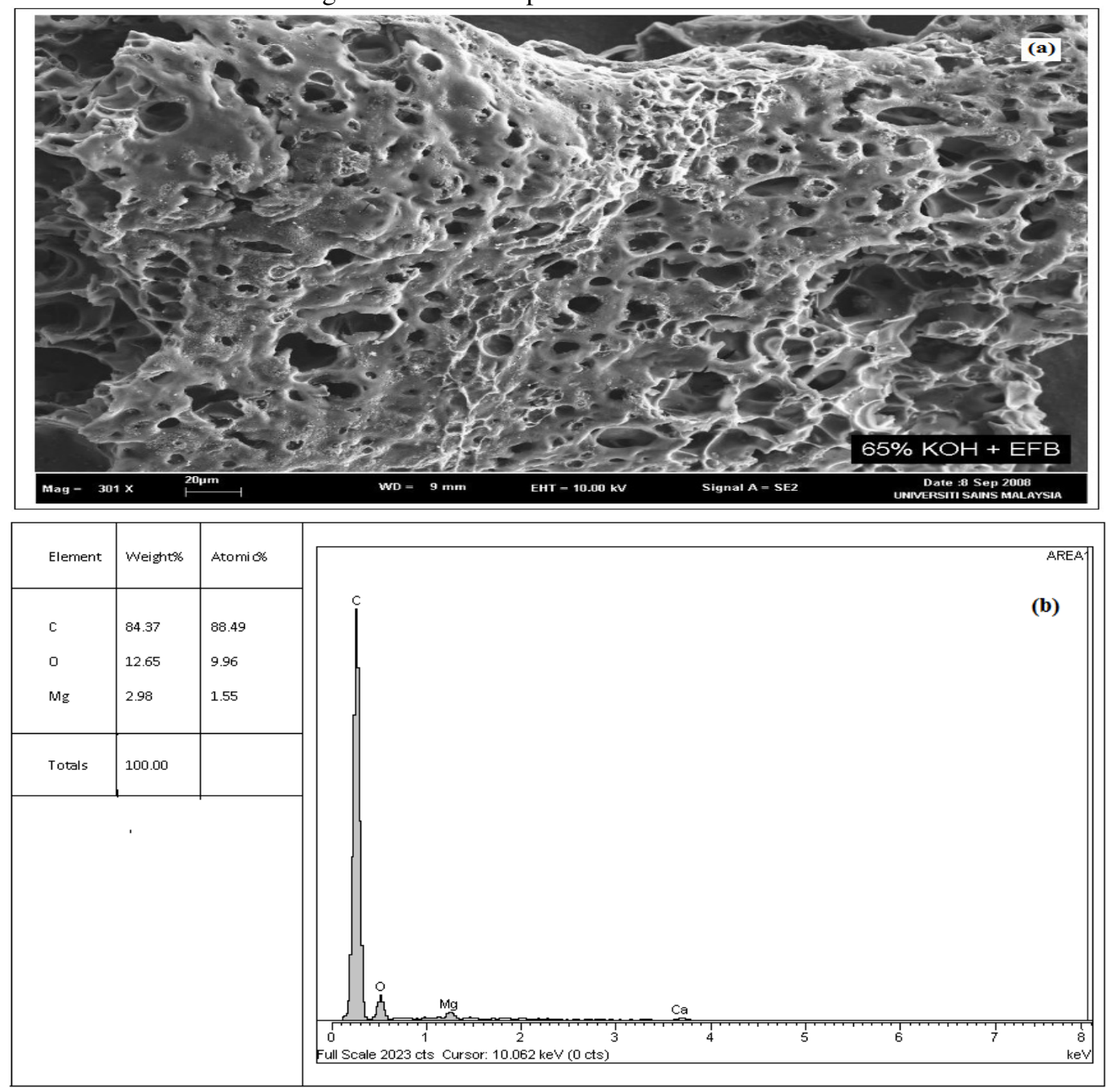

Fig.-6: Structural morphology of activated carbon: (a) external structure, (b) chemical 
RASĀYAN J. Chem.

Vol. 11 | No. 1 |280 - 286 | January - March | 2018

\section{CONCLUSION}

Empty fruit bunch was successfully converted to highly porous activated carbons. The nitrogen adsorption-desorption isotherms of activated carbon showed Type I isotherms which indicated the presence of a highly narrower microporous structures. The average of pore diameters was in the range of $1.52-1.74 \mathrm{~nm}$, and the highest surface area was $1179 \mathrm{~m}^{2} \mathrm{~g}^{-1}$ at an activation temperature of $800^{\circ} \mathrm{C}$. The functional groups on the surface of activated carbon showed more oxygen contents as temperature increased. Surface morphology proved that the activated was clearly full of cavities.

\section{ACKNOWLEDGMENT}

The author is grateful to the Directorate of Research and Public Service (DPPM), Department of Chemistry, Faculty of Mathematics and Natural Sciences, Universitas Islam Indonesia and School of Chemistry Universiti Sains Malaysia, Malaysia for their financial support of this work

\section{REFERENCES}

1. M. O. Ilomuanya, B. Nashirub, N. D. Ifudu, C. I. Igwilo, Journal of Microscopy and Ultrastructure, 5(1), 32 (2017)

2. A. Kumar and H. M. Jena, Applied Surface Science, 365,753(2015).

3. M. Zhi, F.Yang, F. Meng, M. Li, A. Manivannan, N. Wu, ACS Sustainable Chem. Eng., 2(7),1592(2014).

4. N. Saeidi, M. Parvini, and M. R. Sarsabili, International Journal of Engineering, 27(10),1511(2014).

5. M. Ahiduzzaman and A. K. M. Sadrul Islam, American Journal of Physical Chemistry, 5(5), 94 (2016).

6. A. Barroso-Bogeat, M. Alexandre-Franco, C. Fernández-González, V. Gómez-Serrano, Journal of Materials Science \& Technology, 31(8), 806(2015).

7. R. H. Hesas, A. Arami-Niya, W. M. A. Wan Daud, J. N. Sahu, BioResources, 8(2), 2950 (2013).

8. K. Hussaro, American Journal of Environmental Sciences, 10(4),336(2014).

9. K. K. Alau, C.E. Gimba, J. A. Kagbu and B. Y. Nale, Archives of Applied Science Research, 2(5),451(2010).

10. D. Das, D. P. Samal, B. C. Meikap, in Chemical Engineering \& Process Technology. p. 1-7 (2015).

11. M. N. Mahamad, M. A. Ahmad. Zaini and Z. A. Zakaria, International Biodeterioration \& Biodegradation, 102, 274(2015).

12. H. Fałtynowicz, J. Kaczmarczyk, M. Kułażyński, Open Chem., 13,1150(2015).

13. A. Allwar, International Journal of Research in Chemistry and Environment, 3(2),62(2013).

14. G. S. Miguel, G. D. Fowler, C. J. Sollars, Carbon, 41(5),1009(2003).

15. H. Demiral, I. Demiral, F. Tumsek, B. Karabacakoglu, Surface and Interface Analysis, 40, 616 (2008).

16. B. Zhang, P. Xu,Y. Qiu, Q. Yu, J. Ma, H. Wu,G. Luo, M. Xu, H. Yao, Chemical Engineering Journal, 263, 1(2015).

17. M. Olivares-Marín, C. Fernández-González, A. Macías-García, V.Gómez-Serrano, Applied Surface Science, 252(17),5967(2006).

[RJC-2000/2017] 